\title{
Article
}

\section{Flow, affect and visual creativity}

Cseh, Genevieve M., Phillips, Louise H. and Pearson, David G.

Available at http://clok.uclan.ac.uk/13619/

Cseh, Genevieve M., Phillips, Louise H. and Pearson, David G. (2015) Flow, affect and visual creativity. Cognition and Emotion, 29 (2). pp. 281-291. ISSN 0269-9931

It is advisable to refer to the publisher's version if you intend to cite from the work. http://dx.doi.org/10.1080/02699931.2014.913553

For more information about UCLan's research in this area go to http://www.uclan.ac.uk/researchgroups/ and search for < name of research Group>.

For information about Research generally at UCLan please go to http://www.uclan.ac.uk/research/

All outputs in CLoK are protected by Intellectual Property Rights law, including Copyright law. Copyright, IPR and Moral Rights for the works on this site are retained by the individual authors and/or other copyright owners. Terms and conditions for use of this material are defined in the policies page.

\section{CLoK}

Central Lancashire online Knowledge www.clok.uclan.ac.uk

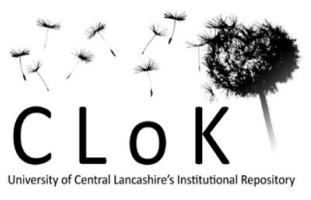




\section{AUTHORS' ACCEPTED MANUSCRIPT:}

This is a preprint of an article accepted for publication in the journal Cognition \& Emotion [copyright Taylor \& Francis]. Cognition \& Emotion is available at http://www.tandfonline.com/loi/pcem20

The published version of the paper, including any corrections made during typesetting, is available online via the journal under the doi:

http://dx.doi.org/10.1080/02699931.2014.913553

Please cite this paper as:

Cseh, G. M., Phillips, L. H., \& Pearson, D. G. (2015). Flow, affect, and visual creativity. Cognition and Emotion, 29(2), 281-291.

\section{Flow, Affect, and Visual Creativity}

Genevieve M. Cseh, Louise H. Phillips, and David G. Pearson ${ }^{1}$

School of Psychology, University of Aberdeen

${ }^{1}$ Correspondence concerning this article should be addressed to Dr David Pearson,

Psychology Department, Anglia Ruskin University, Cambridge, United Kingdom, E-mail: david.pearson@anglia.ac.uk 


\begin{abstract}
Flow (being in the zone) is purported to have positive consequences in terms of affect and performance; however, there is no empirical evidence about these links in visual creativity. Positive affect often - but inconsistently - facilitates creativity, and both may be linked to experiencing flow. This study aimed to determine relationships between these variables within visual creativity. Participants performed the creative mental synthesis task to simulate the creative process. Affect change (pre- vs. post-task) and flow were measured via questionnaires. The creativity of synthesis drawings was rated objectively and subjectively by judges. Findings empirically demonstrate that flow is related to affect improvement during visual creativity. Affect change was linked to productivity and selfrated creativity, but no other objective or subjective performance measures. Flow was unrelated to all external performance measures, but was highly correlated with self-rated creativity; flow may therefore motivate perseverance toward eventual excellence rather than provide direct cognitive enhancement.
\end{abstract}

Keywords: flow; affect; visual creativity; mental synthesis; creativity-mood relationship 
Accounts by famous creators recount eureka highs and depressive lows, therefore creativity and affect have long been linked. Research has focused on how initial affect influences creativity (Baas, De Dreu, \& Nijstad, 2008), with less information on how creativity influences affect. Creative action may influence affect by triggering the experience of flow, a phenomenon and theory first detailed by Csíkszentmihályi (1975; 1990/2002). Flow theory was originally inspired by observing artists, engrossed while working but quickly losing interest once finished, who persevered despite no promise of fortune or fame. Interviews with artists and others involved in activities from mountain climbing to performing surgery revealed flow: an intense, optimal state of consciousness (also known as being in the zone) resulting from highly focused attention on a task in which perceived skills and challenges are balanced. If a task is too easy, people grow bored; too difficult, and anxiety and frustration follow.

Nine key characteristics of the flow experience were identified through Csíkszentmihályi's (1975; 1990/2002) qualitative data: (1) skill-challenge balance; (2) merged action and awareness; (3) clear goals; (4) instant, unambiguous feedback; (5) total focus of attention; (6) sense of control; (7) lack of self-consciousness; (8) altered sense of time; and (9) intrinsic sense of reward. Because many of Csíkszentmihályi’s interviewees referred to feelings of wellbeing surrounding flow, he therefore hypothesised that flow leads to happiness, and that striving for happiness motivates much of human progress. Flow has been proposed as a key cognitive-emotional variable that explains the motivation to engage in activities even in the absence of external reward.

To experimentally examine flow's effects on affective states, Rogatko (2007) tested whether participants' affect changed after experiencing flow. Participants performed any daily 'high flow' activity they wished, from sports to socializing. Those performing 'high flow' activities one hour a week did indeed show increased positive affect and decreased negative affect post-activity. However, a limitation of Rogatko's study was lack of 
consistency in the flow activities or their setting, therefore confounding factors could not be excluded.

Although correlational studies often find links between flow and post-task positive affect (see Landhäußer \& Keller, 2012, for a review), Keller, Bless, Blomann, and Kleinböhl's (2011) experimental manipulation of flow found no link between flow and subsequent positive affect. Indeed they found that the stress hormone cortisol increased during flow, noting that since flow only happens while coping with challenge, it is likely that there will be both uncomfortable and positive feelings while working to overcome difficulty.

Flow research to date has predominantly relied on qualitative analyses, post-hoc correlation, and observing experts performing self-chosen activities outside of laboratory conditions, so it would be useful to investigate these issues in a more controlled experimental task. Visual artists were the original inspiration for the flow concept, but with the exception of a study on flow and musical composition (MacDonald, Byrne, \& Carlton, 2006), flow and creativity have not been explicitly, quantitatively studied together and, to our knowledge, never with regard to visual creativity. This suggests that creativity is a domain in which flow and its relationship to affect needs much more empirical scrutiny, particularly as the creativity-affect relationship is still unclear.

Research on the effects of initial, incidental (Blanchette \& Richards, 2010) affect on creative performance indicates equivocal results. Initial positive affect tends to increase divergent, generative creativity (Baas et al., 2008), because positive affect facilitates associative thought-behaviour patterns (e.g., broaden-and-build theory: Fredrickson \& Branigan, 2012). However, negative affect promotes problem finding, perseverance, and reframing, which also can facilitate creative problem-solving (Kaufmann \& Vosberg, 1997). Research into the reverse causal direction, between creative action and the resultant affective state - or integral affect (Blanchette \& Richards, 2010) - has been less plentiful. In examining the theory that associative thinking improves affect, Akbari Chermahini and 
Hommel (2012) found performing a divergent thinking task elevated positive affect, whereas convergent thinking increased negative affect. If flow has a direct impact on affect - as Csíkszentmihályi (1975) and Rogatko (2007) suggest - flow may also be expected to enhance creativity by increasing positive affect. However, creative activity might itself increase positive affect, whether or not flow is experienced. Therefore it is important to determine whether any relationship between creative action and affect change is correlated to the experience of flow.

Flow has been linked not only to affect, but also to better performance across various domains, particularly sports (Jackson, Thomas, Marsh, \& Smethurst, 2001), but also potentially flow and musical composition (MacDonald et al., 2006). However, Landhäußer and Keller (2012) note the general scarcity of empirical research on flow's relationship to cognitive performance (such as creativity). They also outlined potential direct and indirect reasons behind a flow-performance link: 1) Flow may directly foster cognitive clarity through attentional focus; and/or 2) the positive experience of flow indirectly encourages perseverance, increasing skill growth on a long-term scale. Although correlational studies have found links between flow and performance, it is not clear which of these mechanisms is the driving force behind the link. Furthermore, some experimental studies found no link between flow and objective performance in activities like video games (Keller \& Blomann, 2008). It is possible that any relationship between flow and performance is the effect of high performance on flow, rather than vice versa. Though flow is popularly promoted as a vehicle for achieving both happiness and peak performance, the evidence for a direct link between flow and performance is unclear in relation to functions such as creativity.

To examine how flow, affect, and creativity intersect in the visual arts domain, this study used the creative mental synthesis task (Finke \& Slayton, 1988) to simulate the creative process. This task has been widely used as an experimental analogue for the visual creative process (Pearson, 2007). Affect was measured before and after the task, and flow during the 
task was assessed, with questionnaires. Drawings were subsequently rated on both objective and subjective creative performance measures. Affect change over the course of visual creativity was determined, under controlled laboratory conditions. Relationships between performance (external and self-evaluations), flow, and affect were measured.

Given research showing a relationship between flow and positive affect, e.g., Rogatko (2007), it was predicted higher flow scores would correlate with increased positive and decreased negative affect over the course of the creative task. Flow has also been linked to performance in other domains, including musical creativity (MacDonald et al., 2006), and positive affect can lead to more divergent thought (Baas et al., 2008; Fredrickson \& Branigan, 2012). Therefore, higher flow and positive affect scores were predicted to relate to superior creative performance.

\section{Method}

\section{Participants and Design}

This was a within-subjects correlational study. Fifty-seven psychology undergraduates ( 37 female; age $M=19.60, S D=2.15$ ) were tested in classes of $18-19$ students for course credit. The sample size was determined based on effect sizes reported by MacDonald et al. (2006). We used a larger sample size than MacDonald et al. to ensure our study had greater power to detect significant relationships. Before the three phases of the study began, participants were given a presentation about the creativity task.

\section{Materials and Procedure}

\section{Part 1: Pre-task questionnaire.}

The Positive and Negative Affect Scale (PANAS; Watson, Clark, \& Tellegen, 1988), a widely-used and well-validated inventory of 10 positive (PA) and 10 negative (NA) affect words, was used to measure affect. Although there are many ways to measure and categorise affect, the most common is the bipolar model of positive and negative hedonic tone (Baas et al., 2008), and it is positive affect that has been hypothesised to have relationships to 
creativity (Fredrickson \& Branigan, 2012). The PANAS was selected as it has been used in previous flow-affect research (Rogatko, 2007). The PA and NA words were summed separately, producing total PA and NA scores.

\section{Part 2: The creative mental synthesis task.}

The creative mental synthesis task (Finke \& Slayton, 1988) was originally designed to assess cognitive aspects of the visual creative process, specifically mental imagery. Participants are presented with sets of simple alphanumeric and geometric shapes (Figure 1) and required to mentally combine them into composite patterns. Participants first describe their mental image in writing and then draw a picture underneath. This task was chosen to simulate the creative process because its simplicity requires no artistic background or training, yet it is challenging enough to potentially inspire flow. Synthesis task participants often report task enjoyment and being pleasantly surprised by their own abilities on the task (Finke, Ward, \& Smith, 1992), suggesting flow or positive affect may be induced. Performance data from this task can also be analysed both subjectively and objectively.

Participants were each presented with an identical workbook of 40 three-shape sets adapted from Finke and Slayton's (1988) original procedures (Figure 1), with a 20 minute time limit; the workbook format was chosen to allow for uninterrupted concentration, postulated to facilitate flow (Csíkszentmihályi, 1990/2002). Sketching was allowed (in contrast to the original procedure which emphasised mental synthesis) to provide participants the external support normally available in real-world creative settings, to reduce artificiality and frustration. They were told not to worry about their drawing ability, that they could skip over sets, and not to worry about completing all the sets as the workbook was deliberately too long to allow completion. They were instructed to be as creative as possible while still adhering to the rules of the task (e.g., they could change the size of the shapes but not proportions), and to try to have some fun. In total, 795 valid drawings were produced, each participant producing a mean of $13.94(S D=5.65$; range: $1-29)$. 


\section{Part 3: Post-task questionnaires.}

1) Flow State Scale 2 - Short General (FSS-2; Jackson, Eklund, \& Martin, 2004/2010). This measured degree of flow attained during the task. It is a nine-item 1-5 Likert scale based on the nine components of Csíkszentmihályi’s (1990/2002) flow model. Participants indicated whether each component was experienced in the immediately preceding task. Although there is some disagreement about the measurement of flow (Moneta, 2012), the FSS-2 was chosen for its direct relationship to the most inclusive ninecomponent flow model, and because it is one of the most widely-used and best validated single-administration questionnaires to assess flow during a single activity. Additionally, due to its brevity it was appropriate for administering alongside other questionnaires. For analysis, a mean score was calculated from the nine items.

2) PANAS 2. The PANAS was repeated post-task for comparison to pre-task

affect. Difference scores were calculated by subtracting pre-task from post-task scores. Positive difference scores indicate increase, while negative scores indicate decrease in PA/NA post-task.

3) Post-Task Creativity Questionnaire. This single question gathered participants' ratings of their own perceived creativity on the task overall, on a 1-5 Likert scale (not at all - extremely).

\section{Measures of Creative Performance}

Drawings were scanned, cropped from their workbooks, and checked for validity (whether drawings conformed to task rules); invalid drawings $(6 \%-55 / 850)$ were excluded from further analysis. Two objective measures of creative performance were then calculated for each participant from these images:

1) Productivity. Valid drawings produced within the time limit were counted to produce a productivity score for each participant. Anderson and Helstrup (1993) found quality and quantity of syntheses were affected differently by the conditions of their study, 
suggesting productivity - also referred to as fluency in creativity research - is worthy of inclusion as a separate performance measure.

2) Transformational complexity (Anderson \& Helstrup, 1993) was calculated for each drawing, measuring the number of transformations (i.e., rotations/flips, size changes, embeddings/overlaps) to which the original shapes were subjected to produce the final construct, providing a concrete measure of mental agility and complexity. This is an objective measure so one experimenter rated all the images. To establish reliability a random sample of the images $(10 \% ; \mathrm{n}=80)$ was rated by two further experimenters. Inter-rater reliability was found to be acceptably high at $r(80)=.86, p<.001$. A mean transformational complexity score was calculated from each participant's drawings.

Images were uploaded to a purpose-built online rating system and rated by 21 undergraduate and volunteer judges (18 females; age $M=22.86, S D=7.03$ ). Each judge rated a randomised sequence of 200 drawings. Each image was rated on a 1-5 Likert scale on two subjective factors - (1) correspondence to description and (2) general creativity - by four different judges. These measures were chosen because they were used in previous synthesis task studies (Anderson \& Helstrup, 1993; Finke \& Slayton, 1988).

The intraclass Cronbach's alpha (inter-rater reliability) of ratings for correspondence to description was .67 , and .44 for general creativity.

\section{Analysis}

One-tailed Pearson's bivariate correlation analyses were conducted on the questionnaire and creativity rating data. Scatterplots showed no evidence of outliers.

\section{Results}

\section{Flow and Affect}

A comparison of pre- and post-task positive affect (PA) revealed a significant decrease in overall mean, $t(56)=2.71 ; p<.01$. There was no significant difference between pre- and post-task negative affect (NA), $t(56)=0.08 ; p=.93$. Flow scores were significantly 
related to both pre- and post-task PA and, as predicted, to increased PA between time 1 and 2 (see Table 1 for all descriptive statistics and correlations). Neither pre- nor post-task negative affect (NA) were significantly related to flow. However there was a significant relationship between flow and decrease in NA between time 1 and 2 .

\section{Flow and Creative Performance}

Although flow was highly correlated with self-rated creativity, flow was not significantly related to any of the externally-rated measures of performance. Scatterplots did not show any other significant non-linear relationship. Self-rated creativity was significantly related to productivity, but unrelated to any of the other external performance ratings. A partial correlation between self-rated creativity and productivity remained significant after controlling for flow, $r(53)=.25 ; p<.05$.

\section{Creative Performance and Affect}

Both pre- and post-task PA and both PA and NA change were related to self-rated creativity. PA change across the task was significantly associated with productivity. In contrast to previous creativity-affect research, however, there were no other significant relationships between any of the other external creativity measures and pre-task, post-task, or affect change across the task.

\section{Discussion}

The goal of this study was to explore how the variables of flow, affect, and performance relate to one another in visual creativity.

\section{Affect, Flow, and Creativity}

It was predicted that flow would be associated with improved affect, and the results of this study support this hypothesis. Mean PA decreased across the duration of the task for the sample as a whole, which contradicts Akbari Chermahini and Hommel's (2012) findings that engaging in divergent thinking tasks such as the alternate uses task (AUT) tended to elevate PA. However, the decrease of PA in this study using the synthesis task (also a 
divergent thinking task) likely reflects that the synthesis task is more cognitively challenging than the traditional AUT, given it relies more heavily on the use of mental imagery and working memory faculties, and therefore may be more cognitively fatiguing (Pearson \& Logie, 2000). The significant correlation between PA increase and flow across the sample suggests that flow may have provided a protective barrier against the usual fatiguing aspects of the task, or that sustaining positive affect in the face of a cognitively fatiguing task is vital for the development of flow. This supports Rogatko's (2007) findings with more general 'flow activities', which also found that affect changed for the better alongside flow. However, the link between higher pre-task PA and flow suggests there could be a facilitating effect of initial PA on flow onset. Creativity-affect researchers have long linked PA with more fluent, novel cognition (Baas et al., 2008; Fredrickson \& Branigan, 2012). NA such as anxiety has been shown (Blanchette \& Richards, 2010) to increase vigilance for potential dangers. As flow is defined in part by complete absorption in the task at hand, vigilance to environmental stimuli is reduced. Participants with initially higher PA going into the synthesis task would therefore theoretically be more likely to experience flow because attentional resources would not be directed toward scanning the environment for threats, facilitating deep concentration on the task. However, the often implied causal direction of the flow-affect link is that flow directly improves affect (Csíkszentmihályi, 1990/2002). This cannot be determined by a correlational design, but the link between flow and pre-task affect suggests there may be a facilitating effect of incidental PA on flow. In addition to the PAchange linked to flow in this study, the data suggest there could be a bidirectional causal relationship between flow and PA. However, because participants knew the details of the creativity task before they rated their pre-task affect, personality and expectations (such as high fear of failure) may have had a confounding influence on both pre-task affect and flow (Akbari Chermahini and Hommel, 2012). The procedure order could therefore be altered in future studies to ensure that foreknowledge did not influence pre-task affect. 
Pre- and post-task NA were unrelated to flow, but flow was related to a reduction in NA across the task. However, as in Rogatko's (2007) study, this relationship was weaker than the one between PA change and flow. This suggests flow has a more nuanced relationship to NA, perhaps because flow theoretically depends on encountering and coping well with difficulty and NA (Csíkszentmihályi, 1990/2002). To our knowledge this is the first study to empirically demonstrate a significant link between flow and affect change during visual creativity, under controlled laboratory conditions.

This study does not corroborate findings from previous creativity-affect research finding initial PA related to external measures of creativity (Baas et al., 2008). Here, initial PA was related to self-rated creativity only. However, the PA-creativity relationship depends on many factors including which affective states are measured and the type of creativity task involved (Baas et al., 2008; Kaufmann \& Vosberg, 1997). The synthesis task has not previously been used to study affect; therefore it may be able to add a new dimension to future creativity-affect research.

\section{Flow \& Performance}

Flow often correlates with self-perceived skill, both in previous research (e.g., Jackson et al., 2001) and in the current study, but some have also shown links to external measures of performance (see Landhäußer \& Keller, 2012, for review). To date most flowperformance research has centred on fields with relatively objective standards - e.g., in sports, where self-perceptions and objective measures of performance may be more in tune than in domains with more ambiguous criteria for success. For example, Jackson et al. (2001) found self-perceived performance ratings of athletes were correlated to objective performance in terms of placement in a race. In creative domains, criteria are more subjective, as evidenced by frequent public controversy over new art. Kreitler and Casakin (2009) found some correlations between self-assessed creativity and expert judges' ratings in 
an architectural design study, but this was mostly for dimensions such as fluency and flexibility, which were objective count measures.

The only objective measure of performance linked to self-evaluated creativity in the current study was productivity. The presence of a significant partial correlation between selfrated creativity and productivity, after controlling for flow, suggests that self-evaluations of creativity are mainly related to output quantity. High self-evaluation of skill is a vital component of flow (theoretically, flow depends on perceiving skill as sufficient to meet challenges - a theory supported by the significant correlation between flow and self-rated creativity in this study). However, self-rated skill is only one component in the development of flow and the two variables relate differently to productivity on the task. Furthermore, selfrated skill and flow were not related to one another in the MacDonald et al. (2006) study. Productivity was also the one external performance measure related to positive affect change. These results indicate that positive affect and flow are associated with different aspects of task performance, indicating that they are measuring distinct constructs.

Although not significantly related to flow, productivity was related to both PA change and self-rated creativity. Therefore, creators seemed able to gauge the relative quantity but not quality of their output and based their self-evaluation of creativity mainly on quantity. Judges used Amabile's (1996) consensual assessment technique, which relies on the assumption that everyone has a roughly consistent internal gauge of what constitutes creativity. However, in the current study, self-perceived creativity ratings did not reflect objective quality in terms of transformational complexity, or a shared insight into how others might subjectively evaluate their work.

\section{Limitations \& Directions for Future Research}

A potential limitation of this study is the issue of expertise, as participants were all untrained non-artists. The fact that both creators and judges were equally untrained and not selected for ability might have contributed noise to the subjective creativity assessments, as 
the low inter-rater reliability in this study suggests. Similar low inter-rater reliability in subjective assessments of synthesis task creativity has been reported by McKnight, Ormerod, Sas, and Dix (2006), reflecting the highly subjective nature of defining some aspects of creative quality. Amabile (1996) acknowledged that in some situations expert judges tend to achieve higher inter-rater reliability than non-expert judges using the consensual assessment technique, suggesting sometimes creative standards can be learned, beyond a more general social consensus, particularly when technical skill is required in the task. Getzels and Csíkszentmihályi (1969), however, found agreement between experts was lower than amongst non-experts.

A path for future research might be to compare findings between novice and expert designers/artists and judges to determine whether experts are better predictors of their own creative success according to external criteria, and whether flow and affect then relate more consistently to performance measures. Future studies might also investigate what components creators and judges focus on differentially while evaluating synthesis creativity. However, a danger of only pre-selecting expert participants is that it then becomes more difficult to extract how much of performance is related to flow and how much is related to years of practice and learning. This has been the case in most flow-performance research, and it is a common weakness we sought to remedy by using a task which did not require experience and could be operationalised. Additionally, though subjective rating agreement may be unreliable, it is worth noting that flow also did not correlate with the objective performance measures.

The correlational nature of this study limits conclusions about causation that can be drawn about the relationships between flow and its correlates. However, the repeated measures design enabled us to calculate change in affect during the intervening task, and to determine that this change was related to flow during the task. Additionally, by keeping the task constant and in the laboratory, extraneous factors influencing affect and activity choice 
could be reduced. Future studies could induce different pre-task moods, examine the role of more detailed subtypes of PA and NA (e.g., activating vs. deactivating states: Baas et al., 2008), or manipulate the conditions of the creativity task to further investigate causal patterns in flow, affect, and performance.

\section{Conclusion}

The findings of this study support previously postulated links between flow and improved affect across the course of a constant creativity task. The quantity of creative output was linked to self-perceived creativity and to an increase in positive affect. Links between flow, affect, and quality of creative performance were not found, suggesting that claims that flow and performance are directly linked may not extend to visual creativity. However, the strong relationship found between flow and self-rated creativity highlights that although self-perception may not necessarily match objective reality, the cognitive-emotional experience that accompanies it may be a powerful motivator to ensure perseverance toward learning and eventual excellence. Flow therefore is more likely to be an indirect, long-term influence on performance rather than a direct, immediate one, supporting the second but not the first of the mechanisms posited for a flow-performance link in Landhäußer and Keller's review (2012). However, the relationship between flow, affect, and particularly qualitative creative performance should be explored with different measures of performance and affect, more varied experimental tests of visual creativity, or more expert judges and/or creators. This highlights the need for more empirical work examining the emotional and performance antecedents and consequences of flow in the creative arts domain.

\section{Acknowledgements}

This research was conducted in partial fulfilment of a $\mathrm{PhD}$ studied by the first author at the University of Aberdeen. 


\section{References}

Akbari Chermahini, S., \& Hommel, B. (2012). Creative mood swings: Divergent and convergent thinking affect mood in opposite ways. Psychological Research, 76, 634640. doi:10.1007/s00426-011-0358-z

Amabile, T. M. (1996). Creativity in context: Update to the social psychology of creativity. Boulder, CO: Westview Press.

Anderson, R. E., \& Helstrup, T. (1993). Visual discovery in mind and on paper. Memory and Cognition, 21(3), 283-293. doi: 10.3758/BF03208261

Baas, M., De Dreu, C. K. W., \& Nijstad, B. A. (2008). A meta-analysis of 25 years of moodcreativity research: Hedonic tone, activation, or regulatory focus? Psychological Bulletin, 134(6), 779-806. doi:10.1037/a0012815

Blanchette, I., \& Richards, A. (2010). The influence of affect on higher level cognition: A review of research on interpretation, judgement, decision making and reasoning. Cognition and Emotion, 24(4), 561-595. doi:10.1080/02699930903132496

Csíkszentmihályi, M. (1975). Beyond boredom and anxiety. San Francisco, CA: Jossey-Bass. Csíkszentmihályi, M. (2002). Flow: The classic work on how to achieve happiness (Rev. ed.). London, England: Rider.

Finke, R. A., \& Slayton, K. (1988). Explorations of creative visual synthesis in mental imagery. Memory and Cognition, 16(3), 252-257.

Finke, R. A., Ward, T. B., \& Smith, S. M. (1992). Creative cognition: Theory, research, and applications. Cambridge, MA: MIT Press.

Fredrickson, B. L., \& Branigan, C. (2012). Positive emotions broaden the scope of attention and thought-action repertoires. Cognition and Emotion, 19(3), 313-332. doi:10.1080/02699930441000238 
Getzels, J. W., \& Csíkszentmihályi, M. (1969). Aesthetic opinion: An empirical study. The Public Opinion Quarterly, 33, 34-45.

Jackson, S. A., Eklund, R. C., \& Martin, A. (2010). The flow manual: The manual for the flow scales. Menlo Park, CA: Mind Garden.

Jackson, S. A., Thomas, P. R., Marsh, H. W., \& Smethurst, C. (2001). Relationships between flow, self-concept, psychological skills, and performance. Journal of Applied Sport Psychology, 13, 129-153.

Kaufmann, G., \& Vosberg, S. K. (1997). 'Paradoxical' mood effects on creative problemsolving. Cognition and Emotion, 11(2), 151-170. doi:10.1080/026999397379971

Keller, J., Bless, H., Blomann, F., \& Kleinböhl, D. (2011). Physiological aspects of flow experiences: Skills-demand-compatibility effects on heart rate variability and salivary cortisol. Journal of Experimental Social Psychology, 47, 849-852.

Keller, J., \& Blomann, F. (2008). Locus of control and the flow experience: An experimental analysis. European Journal of Personality, 22(7), 589-607. doi:10.1002/per.692

Kreitler, S., \& Casakin, H. (2009). Self-perceived creativity. European Journal of Psychological Assessment, 25(3), 194-203. doi:10.1027/1015-5759.25.3.194

Landhäußer, A., \& Keller, J. (2012). Flow and its affective, cognitive, and performancerelated consequences. In S. Engeser (Ed.), Advances in flow research (pp. 65-86). New York, NY: Springer. doi:10.1007/978-1-4614-2359-1_4

MacDonald, R., Byrne, C., \& Carlton, L. (2006). Creativity and flow in musical composition: An empirical investigation. Psychology of Music, 34(3), 292-306. doi: $10.1177 / 0305735606064838$

McKnight, L., Ormerod, T. C., Sas, C., \& Dix, A. (2006). As useful as a bicycle to a fish: Exploration versus constraint in creativity. Proceedings of the Cognitive Science Society Conference (pp. 1811-1816). Montreal, Canada: Cognitive Science Society. 
Moneta, G. B. (2012). On the measurement and conceptualization of flow. In S. Engeser (Ed.), Advances in flow research (pp. 23-50). New York, NY: Springer. doi:10.1007/978-1-4614-2359-1_2

Pearson, D. G. (2007). Mental imagery and creative thought. Proceedings of the British Academy, 147, 187-212.

Pearson, D. G., \& Logie, R. H. (2000). Working memory and mental synthesis: A dual task approach. In S. O'Nuallan (Ed.), Spatial cognition: Foundations and applications (pp. 357-359). Amsterdam, Netherlands: John Benjamins Publishing Company.

Rogatko, T. P. (2007). The influence of flow on positive affect in college students. Journal of Happiness Studies, 10(2), 133-148. doi:10.1007/s10902-007-9069-y

Watson, D., Clark, L. A., \& Tellegen, A. (1988). Development and validation of brief measures of positive and negative affect: The PANAS scales. Journal of Personality and Social Psychology, 54(6), 1063-1070. doi:10.1037/0022-3514.54.6.1063

Word Count (body text): 4019 (including acknowledgments statement; 3998 without) 
Table 1.

Descriptive statistics and correlation analyses (significant correlations in bold) between flow, mood, and self- and externally-rated creative performance measures.

\begin{tabular}{|c|c|c|c|c|c|c|c|c|c|c|c|c|}
\hline \multicolumn{13}{|c|}{ DESCRIPTIVE STATISTICS } \\
\hline & \multirow[b]{2}{*}{ Flow } & \multicolumn{2}{|c|}{ Pre-Task } & \multicolumn{2}{|c|}{ Post-Task } & \multicolumn{2}{|c|}{ Change } & \multirow{2}{*}{$\begin{array}{l}\text { Self- } \\
\text { Rated } \\
\text { Creat. }\end{array}$} & \multicolumn{4}{|c|}{ Externally-Rated Performance } \\
\hline & & PA & NA & PA & NA & PA & NA & & $\begin{array}{l}\text { Gen. } \\
\text { Creat. }\end{array}$ & Corresp. & $\begin{array}{c}\text { Trans. } \\
\text { Complex. }\end{array}$ & Product. \\
\hline$N$ & 57 & 57 & 57 & 57 & 57 & 57 & 57 & 56 & 57 & 57 & 57 & 57 \\
\hline Min & 1.78 & 11 & 10 & 10 & 10 & -11 & -5 & 1 & 2.25 & 1.78 & 1.75 & 1 \\
\hline Max & 4.44 & 40 & 29 & 44 & 31 & 9 & 7 & 5 & 3.52 & 3.73 & 4.07 & 29 \\
\hline$M$ & 3.04 & 25.74 & 14.56 & 23.90 & 14.53 & -1.84 & -0.03 & 2.45 & 2.96 & 2.99 & 2.82 & 13.95 \\
\hline$S D$ & 0.56 & 7.13 & 4.89 & 8.42 & 4.65 & 5.14 & 2.68 & 1.19 & 0.27 & 0.43 & 0.50 & 5.65 \\
\hline \multicolumn{13}{|c|}{ CORRELATION ANALYSES } \\
\hline \multicolumn{13}{|c|}{ MOOD } \\
\hline & & \multicolumn{3}{|c|}{$\begin{array}{c}\text { PRE-Task } \\
(\mathrm{N}=57)\end{array}$} & & \multicolumn{3}{|c|}{$\begin{array}{c}\text { POST-Task } \\
(\mathrm{N}=57)\end{array}$} & \multicolumn{4}{|c|}{$\begin{array}{c}\text { CHANGE } \\
(\mathrm{N}=57)\end{array}$} \\
\hline \multicolumn{2}{|c|}{$\begin{array}{l}\text { Flow } \\
(\mathrm{N}=57)\end{array}$} & \multicolumn{2}{|c|}{$\begin{array}{c}\text { PA } \\
r=.51 \\
p<.001^{\star *}\end{array}$} & \multicolumn{2}{|l|}{$\begin{array}{c}\text { NA } \\
r=.01 \\
p=.47\end{array}$} & \multicolumn{2}{|c|}{$\begin{array}{c}\text { PA } \\
r=.68, \\
p<.001^{\star \star}\end{array}$} & \multirow[t]{2}{*}{$\begin{array}{c}\text { NA } \\
r=-.15 \\
p=.13\end{array}$} & \multirow{2}{*}{\multicolumn{2}{|c|}{$\begin{array}{c}\text { PA } \\
r=.40 \\
p=.001^{\star *}\end{array}$}} & \multicolumn{2}{|c|}{$\begin{array}{c}\text { NA } \\
r=-.23 \\
p=.02^{\star}\end{array}$} \\
\hline \multicolumn{10}{|c|}{ PERFORMANCE } & & & \\
\hline
\end{tabular}

Self \& Externally-rated Creative Performance

\begin{tabular}{|c|c|c|c|c|c|c|}
\hline & & & $\begin{array}{c}\text { General } \\
\text { Creativity } \\
(\mathrm{N}=57)\end{array}$ & $\begin{array}{l}\text { Correspond. } \\
\qquad(\mathrm{N}=57)\end{array}$ & $\begin{array}{l}\text { Trans. } \\
\text { Complex. } \\
(\mathrm{N}=57)\end{array}$ & $\begin{array}{l}\text { Productivity } \\
\qquad(\mathrm{N}=57)\end{array}$ \\
\hline & & $\begin{array}{c}\text { Self-rated } \\
\text { creativity } \\
(\mathrm{N}=56)\end{array}$ & $\begin{array}{l}r=.06 \\
p=.66\end{array}$ & $\begin{array}{c}r=-.05 \\
p=.73\end{array}$ & $\begin{array}{c}r=-.12 \\
p=.40\end{array}$ & $\begin{array}{l}r=.33 \\
p=.01^{*}\end{array}$ \\
\hline & & & Flow \& $\mathrm{Cr}$ & ve Performanc & & \\
\hline Flow & & $\begin{array}{c}r=.60 \\
p<.001^{\star *}\end{array}$ & $\begin{array}{l}r=.08 \\
p=.27\end{array}$ & $\begin{array}{l}r=.00 \\
p=.49\end{array}$ & $\begin{array}{l}r=.13 \\
p=.17\end{array}$ & $\begin{array}{l}r=.22 \\
p=.05\end{array}$ \\
\hline & & & Mood \& C & ve Performanc & & \\
\hline PRE- & PA & $\begin{array}{l}r=.29 \\
p=.01^{*}\end{array}$ & $\begin{array}{l}r=.01 \\
p=.47\end{array}$ & $\begin{array}{c}r=-.05 \\
p=.34\end{array}$ & $\begin{array}{c}r=-.08 \\
p=.28\end{array}$ & $\begin{array}{l}r=.00 \\
p=.49\end{array}$ \\
\hline Task & NA & $\begin{array}{l}r=.11 \\
p=.22\end{array}$ & $\begin{array}{c}r=-.07 \\
p=.30\end{array}$ & $\begin{array}{c}r=-.01 \\
p=.48\end{array}$ & $\begin{array}{c}r=-.09 \\
p=.26\end{array}$ & $\begin{array}{c}r=.01 \\
p=.48\end{array}$ \\
\hline POST- & PA & $\begin{array}{c}r=.42 \\
p=.001^{\star *}\end{array}$ & $\begin{array}{c}r=-.08 \\
p=.27\end{array}$ & $\begin{array}{c}r=-.12 \\
p=.19\end{array}$ & $\begin{array}{l}r=.01 \\
p=.47\end{array}$ & $\begin{array}{l}r=.17 \\
p=.11\end{array}$ \\
\hline Task & NA & $\begin{array}{c}r=-.04 \\
p=.39\end{array}$ & $\begin{array}{c}r=-.14 \\
p=.16\end{array}$ & $\begin{array}{c}r=-.02 \\
p=.44\end{array}$ & $\begin{array}{c}r=-.04 \\
p=.39\end{array}$ & $\begin{array}{c}r=-.08 \\
p=.29\end{array}$ \\
\hline $\mathrm{CL}$ & PA & $\begin{array}{l}r=.28 \\
p=.02^{*}\end{array}$ & $\begin{array}{c}r=-.15 \\
p=.14\end{array}$ & $\begin{array}{c}r=-.12 \\
p=.19\end{array}$ & $\begin{array}{l}r=.13 \\
p=.16\end{array}$ & $\begin{array}{l}r=.27 \\
p=.02^{\star}\end{array}$ \\
\hline CIATIVGL & NA & $\begin{array}{l}r=-.26 \\
p=.03^{\star}\end{array}$ & $\begin{array}{c}r=-.11 \\
p=.21\end{array}$ & $\begin{array}{c}r=-.02 \\
p=.43\end{array}$ & $\begin{array}{l}r=.09 \\
p=.24\end{array}$ & $\begin{array}{c}r=-.15 \\
p=.14\end{array}$ \\
\hline
\end{tabular}

* indicates significant at $p<.05$ level

** indicates significant at $p<.01$ level 


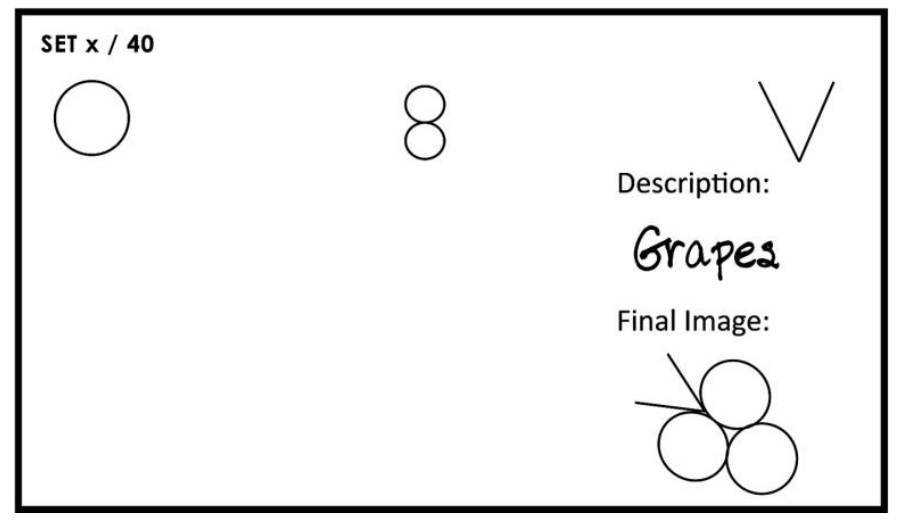

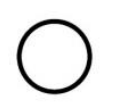

CIRCLE

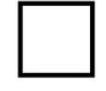<smiles>C1CCC1</smiles>

SQUARE

RECTANG

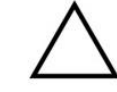

TRIANGLE

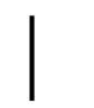

(1)

VERT. LINE
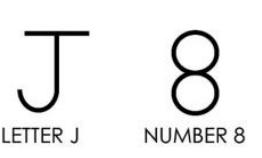$$
\text { (1) }
$$

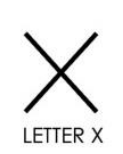

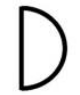

$C$

LETTER C
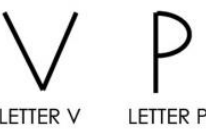

Figure 1. The creative mental synthesis task: Example set as presented to participants, and complete experimental set of 15 shapes from Finke \& Slayton (1988). 